\title{
Different responses in transformation of MDCK cells in 2D and 3D culture by $v$-Src as revealed by microarray techniques, RT-PCR and functional assays
}

\author{
Mira Töyli , Linda Rosberg-Kulha' ${ }^{1}$ Janne Capra², Jussi Vuoristo ${ }^{1}$ and Sinikka Eskelinen ${ }^{1}$
}

Differentiation and transformation of untransformed and ts-Src-transformed canine kidney MDCK cells in 2D and 3D environment were investigated using microarray technique, RT-PCR, confocal microscopy and functional assays. Activated Src induced epithelial-mesenchymal transition (EMT) in 2D environment followed by translocation of junctional proteins to the cytoplasm, without significant changes in protein expression. In 3D environment untransformed MDCK cells formed cell cysts with apical domain facing a lumen, E-cadherin delineating the lateral membranes, ZO-1 at tight junctions and caspase- 3 in apoptotic cells captured within the lumen. This was accompanied by reduced expression of an apoptosis inhibitor, survivin and vesicle transport effectors, rab 7 and 8, whereas rab 5 expression increased. In 3D environment activated Src induced changes in expression of over 100 genes as revealed by microarray analysis, mostly involved in cell signaling, division and energy metabolism. Only response in cytoskeletal components was decreased expression of actin and Arp2/3 by v-Src, whereas two p120catenin binding proteins Kaiso and Nanos increased their expression. Concomitantly, apoptosis was inhibited by v-Src resulting in formation of a sphere with epitheloid cells facing extracellular matrix and undifferentiated cells captured within the cluster. This was accompanied by increased expression of apoptosis inhibitor survivin, as revealed by western blotting. Mitochondrial membrane potential in untransformed MDCK cells was lower than in ts-Src-MDCK cells in early days of cluster formation correlating with the induction of apoptosis. Hence, v-Src activation in 3D environment did not induce EMT, but brought about inhibition of apoptosis and increased proliferation where increased expression of survivin and inhibition of the mitochondrial permeability have a role.

Laboratory Investigation (2010) 90, 915-928; doi:10.1038/labinvest.2010.63; published online 8 March 2010

KEYWORDS: apoptosis; catenins; E-cadherin; epithelial-mesenchymal transition; proliferation

Epithelial tissues, such as colon, kidney, salivary gland or mammary gland must maintain their polarized structure and transport properties during the tissue life span and the junctions are not allowed to be disintegrated during cell proliferation and reorganization. Hence, regulation of cell-cell adhesion is critical for both morphogenesis and homeostasis of adult tissues. ${ }^{1,2}$ The differentiated architecture of an epithelial layer is disrupted in carcinogenesis and filling of the luminal space of epithelial tissues is a hallmark of early epithelial tumors. ${ }^{3}$ Transformed tumor cells populate the lumen and this process requires both enhanced proliferation by oncogenes and inhibition of apoptosis by antiapoptotic signals. The tools to control cell adhesion in tissues range from gene expression to cell proliferation and apoptosis, and cadherins and associated proteins are considered as key players in fulfilling these processes. E-cadherin is crucial for the recognition of the neighboring cells, but it also participates in cell signaling cascades as an associate partner of two catenins, p120catenin and $\beta$-catenin. These two catenins, in turn, are extremely versatile, playing roles in adhesion, nuclear signalling and cancer. ${ }^{4-6}$ Recent studies have revealed the surprising fact that cadherins are necessary for the early recognition of neighboring cells during mesenchymalepithelial transition, whereas $\alpha$-catenin and the actin cytoskeleton are more important in the maintenance of an epithelial phenotype. ${ }^{7-9}$ On the basis of these observations it is obvious that linkages between the components of adherens junctions (AJ), $\alpha$-catenin, $\beta$-catenin, p120catenin, $\alpha$-actinin

\footnotetext{
${ }^{1}$ Biocenter Oulu and the Department of Pathology, Institute of Diagnostics, University of Oulu, Oulu, Finland and ${ }^{2}$ Biocenter Oulu and the Department of Biochemistry, University of Oulu, Oulu, Finland Correspondence: Dr Sinikka Eskelinen, PhD, Department of Pathology, University of Oulu Finland, Biocenter Oulu, Aapistie 5A, Oulu Finland, FIN-90220, Finland. E-mail: sinikka.eskelinen@oulu.fi 
and vinculin, are targets of complex signalling mechanisms regulated by Rho family GTPases, and various kinases and phosphatases. ${ }^{10}$ In addition to cell-cell contacts, integrinmediated cell-ECM contacts are crucial for the differentiation of epithelial cells. Lumen formation requires apoptosis of inner cells, which have lost their matrix connection. This phenomenon, anoikis is induced by both loss of integrinsignalling and loss of growth factor signalling. ${ }^{11}$ Typical feature of cancer cells is resistance to anoikis.

Phosphorylation and ubiquitination are common tools to regulate the stability of the protein complex at the AJs. Tyrosine phosphorylation of AJ components is generally associated with disruption of cell-cell adhesion during epithelial-mesenchymal transition (EMT). For instance, $\beta$-catenin and p120catenin are highly tyrosine phosphorylated in v-Src-transformed cells ${ }^{12,13}$ and phosphorylation of $\beta$-catenin results in dissociation of $\alpha$-catenin from $\beta$-catenin, a feature that strongly correlates with defective E-cadherinmediated adhesion. ${ }^{14,15}$ Also E-cadherin is a tyrosine kinase substrate. Receptor and non-receptor tyrosine kinases are capable of phosphorylating the cytoplasmic tail of E-cadherin resulting in its internalization and subsequent degradation. ${ }^{12,16}$ To study the malignant transformation process in cell culture, an inducible system is required. The ts-Srctransformed MDCK cells designed by Behrens et al. ${ }^{12}$ are an useful tool in studies of transformation process: when cultivated at $+40.5^{\circ} \mathrm{C}$, they behave as normal epithelial cells, whereas after a shift to $+35^{\circ} \mathrm{C}, \operatorname{Src}$ tyrosine kinase is activated and the cells are transformed mesenchymal having poor cell-cell contacts and flattened shape. ${ }^{12,13,17}$ This feature gives us a tool in analyzing the regulatory factors of the transformation process induced by $\mathrm{v}$-Src oncogene only by changing the culture temperature.

\section{MATERIALS AND METHODS}

\section{Cell Strains and Culture Conditions}

Madin-Darby canine kidney cells (MDCK, strain II, kindly provided by Professor Kai Simons, EMBL, Heidelberg, FRG), and the ts-Src MDCK cells, provided by Professor Walter Birchmeier and Dr. Jürgen Behrens (Max Delbrück Center for Molecular Medicine, Berlin, Germany; ${ }^{12}$ ) were cultivated in a $2 \mathrm{D}$ environment as described earlier by Rahikkala et al. ${ }^{17}$

For analysis of DNA expression, RT-PCR, western blotting of survivin and mitochondrial activity both cell lines were cultivated in three-dimensional Matrigel mixture (BD Biosciences, San Jose, CA, USA) as described by Debnath et al. ${ }^{18}$ To make the 3D matrix more supportive for western blotting of cadherin and for phenotype analysis by confocal microscopy the cells were cultivated in a mixture of Matrigel (75\%) and collagen I (25\%). Collagen I (BD Biosciences, rat tail collagen I, high concentration) was prepared as described by Torkko et al. ${ }^{19}$ Ice cold Matrigel and Collagen I were mixed, the cell suspension was added and the mixture pipetted into flexiPERM reusable cell culture chambers (Greiner Bio-One, Frickenhausen, Germany) sealed on a microslide. After polymerization of Matrigel new medium supplement $(200 \mu \mathrm{l}$ D-MEM with 5\% FBS) was given. The medium was changed every other day.

In some experiments, the inhibitor of Src kinase, pp2 (Tocris Bioscience, Bristol, UK) was used. It was dissolved in DMSO in a concentration of $10 \mathrm{mM}$ and used for experiments in a concentration of $50 \mu \mathrm{M} .^{13}$

\section{Antibodies and other Reagents}

MDCK-specific anti-cadherin mouse mAb (rrl) detecting extracellular domain of E-cadherin was purchased from Developmental Studies Hybridoma Bank (Iowa City, Iowa, USA $\left.;^{20}\right)$. A monoclonal E-cadherin mouse antibody produced against intracellular domain of E-cadherin with or without FITC conjugate was purchased from BD Biosciences (cat. no. 610181; San Jose, CA, USA) and polyclonal pancadherin rabbit antibody, detecting cytoplasmic domain of several cadherins was purchased from Invitrogen (cat. no. 71-7100; Carlsbad, CA, USA). Anti- $\beta$-catenin mouse mAb (C19220) and anti-p120catenin mouse mAb (P17920) were purchased from BD Biosciences. Anti- $\alpha$-catenin mouse $\mathrm{mAb}$ (IG5) was provided by Professors Keith Johnson and Margaret J. Wheelock (Nebraska Medical Center, Omaha, NE, USA). Rabbit polyclonal anti- $\beta$-catenin antibody was purchased from Invitrogen (Cat. No 71-2700), rat monoclonal antibody to ZO-1 was from Chemicon (Temecula, CA, USA), rabbit polyclonal antibody to caspase-3 cleaved fraction was purchased from Cell Signaling Technology (cat. No 9661S; Danvers, MA; USA). A rabbit polyclonal antibody against survivin (ab469) was purchased from Abcam (Cambridge, UK). Src Antibody Sampler Kit containing Phospho-Src Family (pY416) antibody (no. 2101) for activated Src and Src (36D10) antibody (no. 2109) for cellular total Src were purchased from Cell Signaling Technology. Anti-avian Src, clone EC10 antibody (05-185) was purchased from Upstate (Lake Placid, NY, USA).

Alexa 568 phalloidin, Alexa 488 and Texas Red goat antimouse antibodies, TRITC antirat antibody, DAPI (D1306), Hoechst33342 (H-1399), Mitotracker Green FM (M7514) and Mitotracker Orange CM-H2TMRos (M7511) were from Invitrogen. HRP (peroxidase) -conjugated anti-mouse and anti-rabbit antibodies and unconjugated mouse IgG were from Jackson ImmunoResearch Laboratories (West Grove, PA, USA).

\section{Microarray Analysis}

RNA was isolated from the 2D and 3D specimens using Trizol Reagent and purified with the aid of Qiagen RNeasy kit according to the manufacturer's instructions. Experimental procedures for GeneChip were performed according to the Affymetrix GeneChip Expression Analysis Technical Manual. In essence, using $5 \mu \mathrm{g}$ of total RNA as template doublestranded DNA was synthesized by means of the One-cycle cDNA synthesis kit (Affymetrix) and T7-(dT)24 primer. The DNA was purified using GeneChip Sample Cleanup Module 
(Qiagen). In vitro transcription was performed to produce biotin-labeled cRNA using an IVT-labeling kit (Affymetrix), biotinylated cRNA was cleaned with a GeneChip Sample Cleanup Module (Qiagen), fragmented from 35 to $200 \mathrm{nt}$, and hybridized to Affymetrix Canine arrays, which contain approximately 23000 canine transcripts. After being washed, the array was stained with streptavidin-phycoerythrin (Invitrogen), staining signal amplified by biotinylated antistreptavidin (Vector Laboratories) followed by second staining with streptavidin-phycoerythrin, and then scanned on GeneChip Scanner 3000.

The expression data was analysed using Affymetrix GeneChip Operating System (Affymetrix) and dChip software. ${ }^{21}$

\section{RNA Isolation for RT-PCR}

RNA was extracted from 2D and 3D specimens according to the instructions of the Qiagen RNAeasy kit (no 74104) and used for synthesis of cDNA. The expression of Rab5, Rab7, Rab8, survivin were analysed using Ubiquitin-Specific Peptidase as a control. The forward and reverse primers shown in Figure 3 were ordered from Sigma-Aldrich (St. Louis, MO, USA). The RT-PCR analysis was performed using Stragene Brilliant SybrGreen QPRC Mastermix (600548) and Stragene Mx3005P RT-PCR equipment. The data was analysed with MxPro -software provided by Stragene (La Jolla, CA, USA).

\section{Immunoblotting Analysis of Cadherin, Src and Survivin Expression}

For analysis of cadherin expression, the cells grown in $2 \mathrm{D}$ or 3D environments were separated in Triton soluble and insoluble fractions, proteins were resolved on 7.5\% SDS-PAGE and transferred onto nitrocellulose membrane. The blots were incubated with the primary antibodies for $2 \mathrm{~h}$ followed by $1-\mathrm{h}$ incubation with horseradish peroxidase-conjugated secondary antibody. The blots were developed for $2 \mathrm{~min}$ in light with a detection liquid $(10 \mathrm{ml} \mathrm{0.1} \mathrm{M} \mathrm{Tris-} \mathrm{HCl} \mathrm{pH} \mathrm{8.5,35 \mu l} 250 \mathrm{mM}$ luminol in DMSO and $15 \mu \mathrm{l} 90 \mathrm{mM}$ p-coumaric acid in DMSO and $3 \mu \mathrm{l} 30 \% \mathrm{H}_{2} \mathrm{O}_{2}$ ) and the emitted light collected using FujiFilm LASS 3000 gel imaging device (FUJI).

Survivin was detected by using total cell lysates. The cells were scraped from dishes, dissolved on ice in cell lysis buffer (50 mM Tris- $\mathrm{HCl}, \mathrm{pH}$ 7.4, 1 \% NP-40, $0.25 \%$ Na-deoxycholate, $150 \mathrm{mM} \mathrm{NaCl}, 1 \mathrm{mM}$ EDTA, $1 \mathrm{mM}$ PMSF, $1 \mathrm{mM}$ $\mathrm{Na}_{3} \mathrm{VO}_{4}, 1 \mathrm{mM} \mathrm{NaF}, 1 \mu \mathrm{g} / \mathrm{ml}$ aprotin, $1 \mu \mathrm{g} / \mathrm{ml}$ leupeptin and $1 \mu \mathrm{g} / \mathrm{ml}$ pepstatin), sonicated and incubated on ice for $30 \mathrm{~min}$, thereafter the suspension was centrifuged for $2 \mathrm{~min} \times 10000 \mathrm{~g}$ at $+4^{\circ} \mathrm{C}$ and the supernatant used for protein determination and gel electrophoresis. The proteins were resolved on 15\% SDS-PAGE and transferred onto nitrocellulose membrane. Thereafter the procedure was continued as for cadherin. For cell lysate from Matrigel-collagen cultures, the specimens were treated by $0.01 \%$ collagenase A (Roche) for $30 \mathrm{~min}+37^{\circ} \mathrm{C}$ before adding the cell suspension to cell recovery solution (BD Biosciences). After incubation on ice for 30 min the cells were collected by centrifuging at $300 \mathrm{~g}$ for $5 \mathrm{~min}$ at $+4^{\circ} \mathrm{C}$. The pellet was dissolved in the cell lysis buffer and the procedure continued as described above.

Src expression and activity was analysed by western blotting with specific antibodies to activated Src (pY416), total cellular Src (36D10) and to avian Src (EC10) according to the instructions given by Cell Signaling Technologies. Briefly, the cells were lysed in $1 \times$ SDS sample buffer, scraped, sonicated, boiled and, after cooling on ice and centrifugation, the supernatant was used for protein determination and gel electrophoresis. The proteins were resolved on 10\% SDSPAGE and transferred onto nicrocellulose membrane. Thereafter the procedure continued as for cadherin.

\section{Immunostaining for Confocal Fluorescence Microscopy}

To analyze the colocalization of E-cadherin with catenins the src-MDCK cells grown on cover slips either at $+40.5^{\circ} \mathrm{C}$ or at $+35^{\circ} \mathrm{C}$ to confluency were fixed and stained for E-cadherin together with $\alpha$-, $\beta$ - or p120catenin antibodies as described by Palovuori et al. ${ }^{13}$ and Ling et al. ${ }^{22}$ Briefly, the cells were fixed with $4 \%$ formaldehyde (FA) in PBS for 15 min, blocked with $50 \mathrm{mM} \mathrm{NH}_{4} \mathrm{Cl}$ solution for $30 \mathrm{~min}$, permeabilized with $0.1 \%$ saponin in PBS for $30 \mathrm{~min}$, followed by short post fixation with ethanol at $-20^{\circ} \mathrm{C}$. The cells were incubated for 30 min with catenin antibodies and thereafter for 30 min with Texas Red antimouse antibody. To block antimouse antibody binding sites the cells were incubated with non-conjugated mouse IgG $(0.5 \mu \mathrm{g} / \mathrm{ml}$ in PBS $)$ for $30 \mathrm{~min}$, followed by $60 \mathrm{~min}$ incubation with a mixture of FITC-conjugated anti-E-cadherin antibody and DAPI. After washings the cells were mounted in an Immu-Mount mounting liquid (Shandon, Pittsburg, PA, USA).

The cells grown in 3D mixture of Matrigel and collagen were fixed with $2 \%$ FA in PBS for 20 min, blocked with $0.1 \%$ BSA, $0.2 \%$ Triton X-100, $0.05 \%$ Tween- 20 and $10 \%$ FBS in PBS for $30 \mathrm{~min}$, incubated overnight in $+4^{\circ} \mathrm{C}$ with the primary antibody, for $1 \mathrm{~h}$ at room temperature with the secondary antibody and DAPI. The samples were refixed with $2 \%$ FA in PBS for 20 min at room temperature, washed and mounted with Immu-Mount.

\section{Recycling Experiments}

For analysis of cadherin internalization the cells were incubated for $30 \mathrm{~min}$ on ice with $\mathrm{rr} 1$ anti-E-cadherin antibody $(20 \mu \mathrm{g} / \mathrm{ml})$ after which the cells were warmed to $+40.5^{\circ} \mathrm{C}$ or $+35^{\circ} \mathrm{C}$ for a given time period. The cells were fixed and permeabilized as described by Palovuori et al., ${ }^{13}$ the specimens incubated with polyclonal anti- $\beta$-catenin antibody, followed by incubation with Alexa 488 antimouse and Texas Red antirabbit antibodies together with DAPI and mounted as described above.

\section{Confocal Microscopy}

The fixed specimens were viewed with Olympus FluoView1000 confocal microscope using $\times 60$ oil objectives 
and appropriate filter sets for blue, green and red channel. From 2D specimens 6 to 8 cell layers and from 3D cell cysts 20 to 30 cell layers were collected using step size $0.5 \mu \mathrm{m}$ through the specimen. The images were collected and saved using the Olympus software and the presentations were prepared using the Corel Draw graphical program.

Co-localization analysis of internalized E-cadherin with $\beta$-catenin was carried out using the Olympus FluoView1000 software as explained in Table 1.

\section{Measurement of Mitochondrial Activity}

The untransformed and ts-Src-transformed MDCK cells grown in 3D Matrigel were labeled with a mixture of Hoechst $(1 \mu \mathrm{g} / \mathrm{ml})$, Mitotracker Green $(0.2 \mu \mathrm{M})$ and Mitotracker Orange $\mathrm{CM}-\mathrm{H}_{2} \mathrm{TM}$ Ros $(0.2 \mu \mathrm{M})$ for $15 \mathrm{~min}$ in the cell culture stove. The cell clusters were illuminated under an Olympus CellM video microscope using a $40 \times$ water immersion objective and appropriate filters for blue, green and red channel. After illumination the cell culture dishes were returned to the cell culture stove and experiments repeated every day. The image intensities of selected regions of interest (ROIs) were measured using the Olympus CellM software and the ratio of the intensity on red channel to that on green channel was taken as a measure of the proportion of active mitochondria from the total mitochondrial mass. The statistical analysis of the results was performed using Microsoft Excel software.

\section{RESULTS}

\section{Microarray Analysis of DNA Expression in 2D and 3D Environment}

The summary of gene expression analysis is shown in Figures 1 and 2 and a more thorough analysis of the results at various circumstances are collected in Supplementary Tables S1-S3 in the supplement part of this work. The western blotting analysis of the expression and activity of Src in untransformed MDCK cells and ts-Src-transformed MDCK cells grown in $2 \mathrm{D}$ environment is shown in Figure 1b. The untransformed MDCK cells showed positive staining only with the antibody to total c-Src. Avian Src and total c-Src were detected in blots of the ts-Src MDCK cells grown at both $+40.5^{\circ} \mathrm{C}$ and $+35^{\circ} \mathrm{C}$ temperature, whereas the signal for activated pY416 Src was very strong in specimens of cells grown at $35^{\circ} \mathrm{C}$ and very faint in cells grown at $40.5^{\circ} \mathrm{C}$. Hence, $\mathrm{v}$-Src was expressed both at non-permissive and permissive temperature, but activated only at permissive $+35^{\circ} \mathrm{C}$. This is in line with the results obtained by de Diesbach $e t a l .{ }^{23}$ on the same ts-Src MDCK cell line transfected with exactly the same clone of $\mathrm{v}$-Src.

We wished to elucidate the gene expression profile related to activated Src kinase and analyze its impact on the cell phenotype both at 2D and 3D environment. The untransformed MDCK cells, ts-Src MDCK cells grown at $+40.5^{\circ} \mathrm{C}$ and ts-Src-MDCK cells grown at $+35^{\circ} \mathrm{C}$ on cell culture dishes in the presence of Src inhibitor pp2 showed an epithelial morphology and a mesenchymal phenotype was dominant in ts-Src-MDCK grown at $+35^{\circ} \mathrm{C}$ without inhibitor (Palovuori et al. ${ }^{13}$, Figure 4). This gives us a tool to compare the gene expression pattern in epithelial cells to that in mesenchymal cells separately in three different circumstances:

(1) ts-Src MDCK cells grown at $+40.5^{\circ} \mathrm{C}$ vs ts-Src MDCK cells grown at $+35^{\circ} \mathrm{C}$

(2) MDCK cells grown at $+35^{\circ} \mathrm{C}$ vs ts-Src MDCK cells grown at $+35^{\circ} \mathrm{C}$

(3) ts-Src MDCK cells grown at $+35^{\circ} \mathrm{C}$ in the presence of pp2 vs ts-Src MDCK cells grown at $+35^{\circ} \mathrm{C}$.

In each case thousands of genes have changed their expression level. The results both in $2 \mathrm{D}$ and $3 \mathrm{D}$ conditions are presented in Figure 1a and Supplementary Tables S1 and S2. The lowest number of genes changed was between ts-Src

Table 1 Co-localization of internalized surface cadherin and $\beta$-catenin in v-Src-transformed MDCK cells

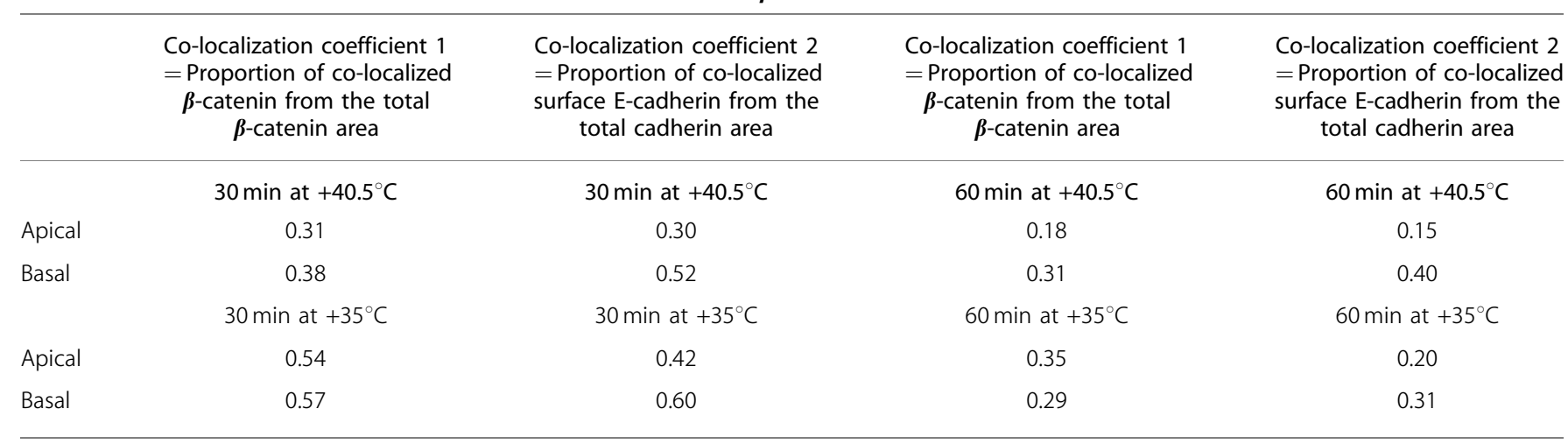

Co-localization analysis of internalized antibody-labelled surface cadherin with $\beta$-catenin in v-Src-transformed MDCK cells 30 or 60 min after warming to $+40.5^{\circ} \mathrm{C}$ or $+35^{\circ} \mathrm{C}$. Quantitative analysis was carried out using Olympus Fluoview1000 software after thresholding to eliminate noise and background from the images. According to Handbook of Confocal Microscopy ${ }^{49}$ the use of co-localization coefficients are the most biologically useful, representing the proportion of pixels from each channel that contribute to the co-localized area. Co-localization coefficients are higher at the 30 min time point, especially at $+35^{\circ} \mathrm{C}$, whereas in 60 min at $+40.5^{\circ} \mathrm{C}$ apical cadherin vesicles are practically void of $\beta$-catenin. 

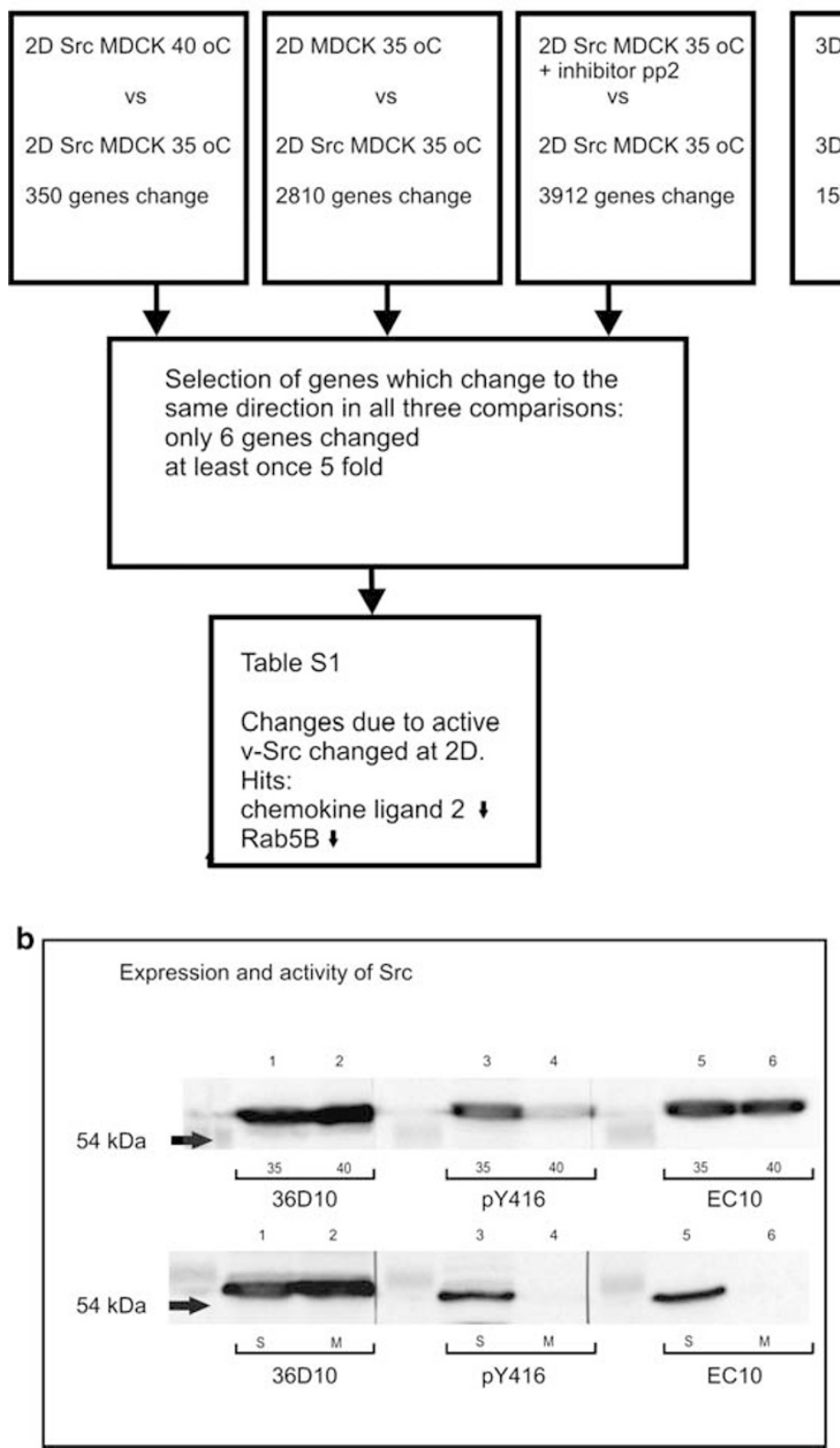

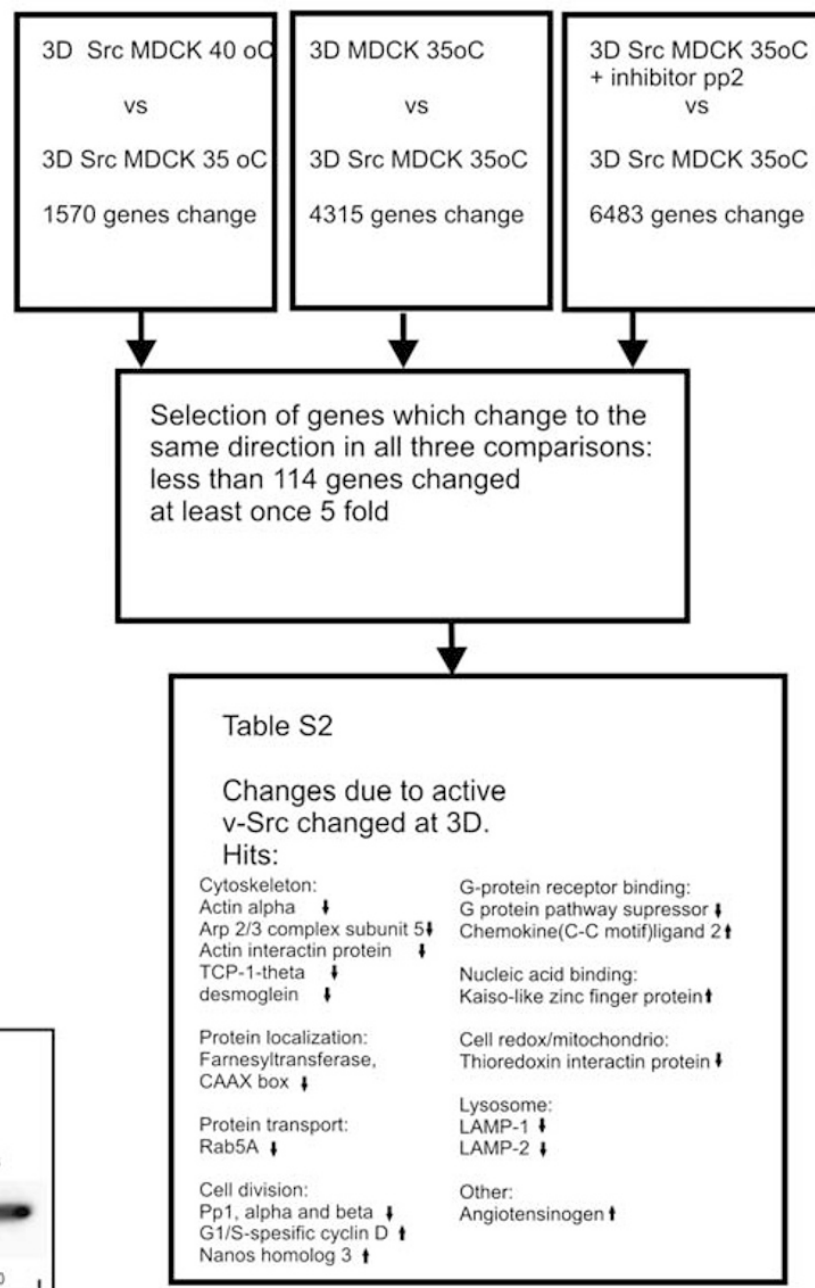

Changes due to active

$v$-Src changed at 3D.

Cytoskeleton:

Nucleic acid binding:

Kaiso-like zinc finger protein $\mathbf{t}$

Lysosome

LAMP-2

Other:

Pp1, alpha and beta +

Nanos homolog 3 t

Figure 1 (a) Summary of the changes in gene expression in untransformed and v-Src-transformed MDCK cells grown in 2D and 3D environments at various temperatures to confluency or cell clusters. The mRNA was harvested from the specimens, converted to CDNA and used to probe the Affymetrix Canine arrays as described in Materials and Methods. We took three specimens with epithelial phenotype in 2D and 3D environment: (1) untransformed MDCK cells, (2) v-Src-transformed MDCK cells grown at non-permissive temperature, $+40.5^{\circ} \mathrm{C}$ and (3) v-Src-transformed MDCK cells grown at $+35^{\circ} \mathrm{C}$ with Src activity inhibited by pp2 and compared the changes in gene expression to v-Src-transformed MDCK cells grown at permissive temperature, $+35^{\circ} \mathrm{C}$ without inhibitor. The changes which took place at the same direction in all three comparisons were considered specific to Src activation. The results for 2D environment are shown in Supplementary Table 1 and 3D environment in Supplementary Table 2 in the supplement part of this work and the highlights are indicated in (a). (b) The upper panel shows immunoblot analysis of expression of Src in cell lysates from v-Src-transformed MDCK cells grown to confluency at $2 \mathrm{D}$ at $+35^{\circ} \mathrm{C}$ (lanes 1, 3 and 5) or $+40.5^{\circ} \mathrm{C}$ (lanes 2, 4 and 6) and the lower panel shows expression of Src in v-Src-transformed MDCK cells grown to confluency at $2 \mathrm{D}$ at $+35^{\circ} \mathrm{C}$ (lanes 1,3 and 5) and untransformed MDCK cells grown to confluency at $2 \mathrm{D}$ at $+37^{\circ} \mathrm{C}$ (lanes 2,4 and 6 ) visualized with a set of antibodies to Src: 36D10 towards total c-Src, pY416 towards Src phosphorylated on tyrosine 416, EC10 towards avian Src. A $60 \mathrm{kDa}$ band corresponding to total c-Src was observed in both untransformed and v-Src-transformed MDCK cells grown at 2D (lanes 1 and 2), to activated v-Src in v-Src-transformed MDCK cells grown to confluency at $2 \mathrm{D}$ at $+35^{\circ} \mathrm{C}$ (lane 3) and faintly in v-Src-transformed MDCK cells grown to confluency at $2 \mathrm{D}$ at $+40.5^{\circ} \mathrm{C}$ (lane 4 in upper panel) and to avian Src in v-Src-transformed MDCK cells grown to confluency at $2 \mathrm{D}$ at $+35^{\circ} \mathrm{C}$ (lane 5 upper and lower panel) or at $+40.5^{\circ} \mathrm{C}$ (lane 6 upper panel). 
Microarray analysis of gene alterations due to complex 3D environment

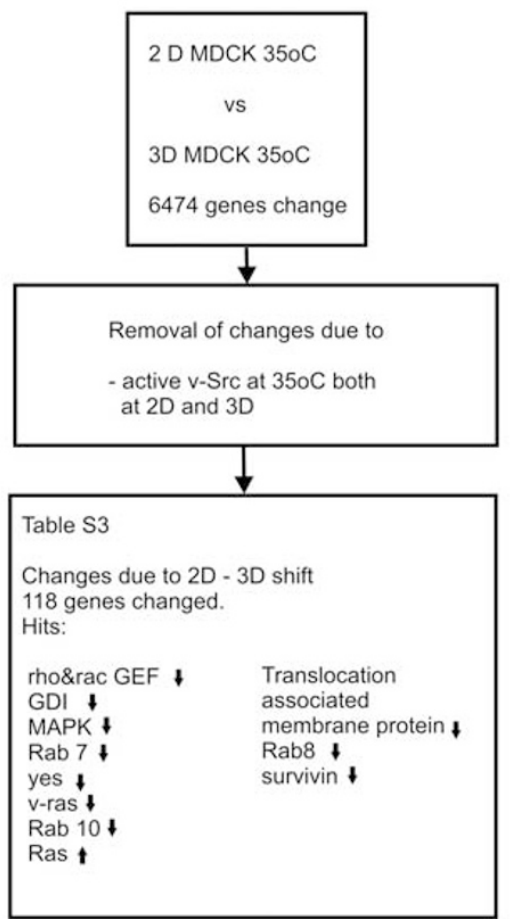

Figure 2 Summary of the changes in gene expression in untransformed MDCK cells grown in 2D and 3D environments to confluency or cell clusters. The mRNA was harvested from the specimens, converted to CDNA and used to probe the Affymetrix Canine arrays as described in MATERIALS AND METHODS. The shift of untransformed MDCK cells to a more complex 3D matrix induced a change of 6474 gene expression levels (Figure 2,

Supplementary Table 3). However, after removing from the files the genes also altered by the $v$-Src, only 118 genes could be linked to a shift from 2D to $3 \mathrm{D}$ environment: very minor changes had occurred in the expression levels of cadherins or other junctional complexes and the most striking feature was a change in the expression of rab proteins. Also the expression of a rho/racGEF and GDI decreased. Especially interesting was a decrease in the expression level of an inhibitor of apoptosis (IAP) survivin.

MDCK cells grown at $+40.5^{\circ} \mathrm{C}$ vs ts-Src MDCK cells grown at $+35^{\circ} \mathrm{C}$ and the highest between transformed cells with and without Src inhibitor. This might reflect the fact that $\mathrm{Src}$ is leaky at $+40.5^{\circ} \mathrm{C}$, as shown in Figure $1 \mathrm{~b}$. On the other hand, the larger number of gene changes seen when the inhibitor pp2 is used relative to the changes observed between ts-Src MDCK and MDCK cells (Figure 1a) could be due to the fact that pp2 is also inhibiting some other Src-family kinases as well as $\mathrm{Src}^{24}$ For further analysis we have picked only those gene alterations which have occurred in the same direction in each three comparisons and considered these genes as a specific response to activated Src. Using this approach we might have lost some genes induced by Src activation, but the remaining hits can be considered relevant to the transformation process induced by $\mathrm{v}-\mathrm{Src}$. A striking feature was the lack of changes in the expression of any catenins or cadherins upon EMT in v-Src transformed cells. We can conclude that at least during a short time period the alterations in the cell phenotype by $\mathrm{v}$-Src in cells grown on dishes are caused by signalling cascades affecting protein interactions at cell junctions rather than lowered expression of junctional proteins. ${ }^{12-16}$

The same analysis was carried out on specimens grown in a 3D environment and the results are collected in Figure 1a and Supplementary Table S2. The majority of genes changed upon Src activation were related to cell signalling, cell division and energy metabolism. Only response in cytoskeletal components was decreased expression of actin and Arp2/3 by $\mathrm{v}$-Src. Relevant to malignant transformation might be the fact that two p120catenin-binding proteins, Kaiso and Nanos, increased their expression due to $\mathrm{v}$-Src activation. Nanos is a zinc finger protein, which has an evolutionarily conserved function in embryonic patterning and germ line development. ${ }^{25}$ It is downregulated by E-cadherin, interacts with p120catenin and induces its cytoplasmic translocation as well as strong migratory and invasive properties. ${ }^{25}$ Kaiso also belongs to zinc finger protein family, which forms a complex with p120catenin, but also functions as a transcriptional repressor. ${ }^{26}$ Taken into account that p120catenin is a strong substrate of $\mathrm{v}$-Src our findings might give a clue on how transformation processes in $\mathrm{v}$-Src transformated cells might proceed.

The shift of untransformed MDCK cells to a more complex 3D matrix induced a change in 6474 gene expression levels (Figure 2, Supplementary Table S3). However, after removing from the files the genes also altered by the v-Src, only less than 118 genes could be linked to a shift from $2 \mathrm{D}$ to 3D environment: very minor changes had occurred in the expression levels of cadherins or other junctional complexes and the most striking feature was a change in the expression of rab proteins. Also the expression of a rho/racGEF and GDI decreased. Especially interesting was a decrease in the expression level an inhibitor of apoptosis (IAP) survivin.

\section{RT-PCR Analysis of DNA Expression in MDCK Cells Grown in 2D and 3D with and without v-Src}

Both vesicle transport and apoptosis are crucial for differentiation processes. Therefore, we confirmed the microarray analysis using RT-PCR analysis of following proteins: rab5, rab7, rab8 and survivin (Figure 3). The expression of v-Src in cells grown on dishes had very minor changes in these target proteins. In contrast, the shift of MDCK cells to 3D environment induced 3.7-fold increase in rab5, 3-fold decrease in rab 7, 5-fold decrease in rab8 and 5.5-fold decrease in survivin expression. In v-Src-transformed MDCK cells grown in 3D environment the expression levels of rab5, rab7, rab8 and survivin again increased when compared with untransfected MDCK cells in 3D.

\section{Western Blotting}

We wished to confirm the microarray results on the negligible effect of v-Src on the expression of E-cadherin using western blotting with three antibodies to cadherin, one detecting the cytoplasmic domain and another detecting the extracellular 

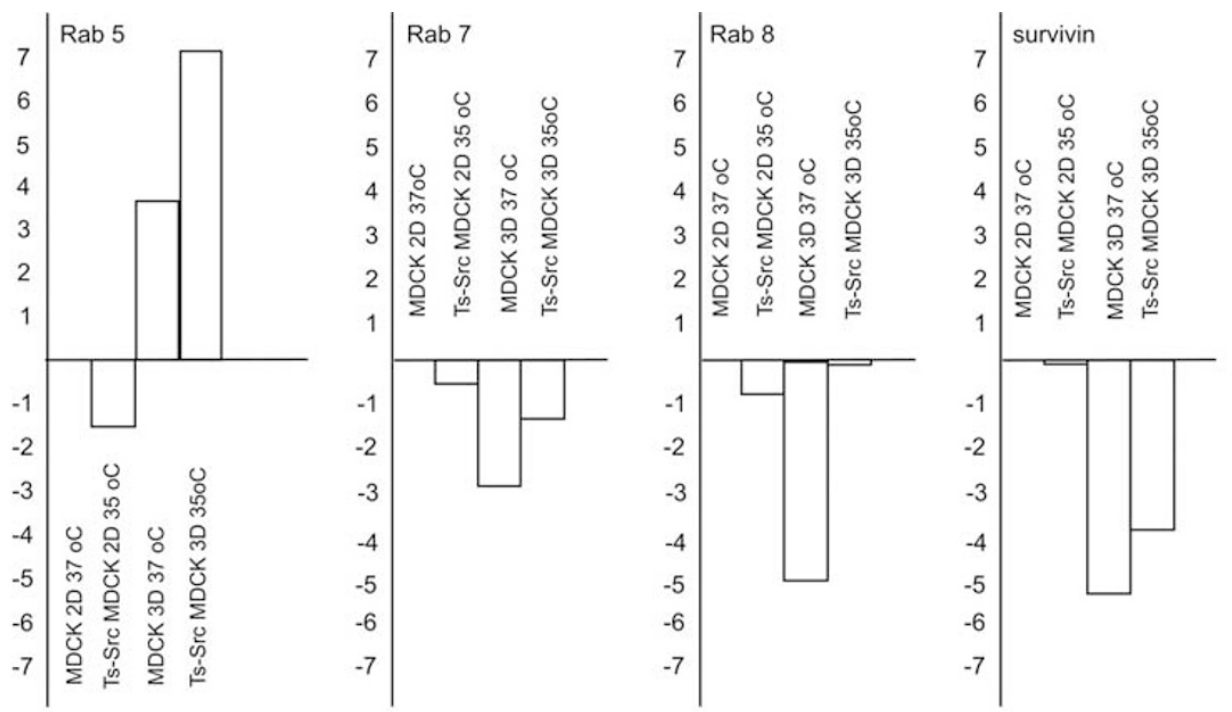

\begin{tabular}{|c|c|c|c|}
\hline \multicolumn{4}{|c|}{ Primers used in RT - PCR } \\
\hline Templates & Primer sequences & $\begin{array}{l}\text { size of } \\
\text { PCR'ed } \\
\text { fragments }\end{array}$ & Tm oC \\
\hline Rab 5 & $\begin{array}{l}\text { Sense 5' TTTTAGTGCAGTGGGAAACA } \\
\text { Antisense 5' GAACGCCATCAATTTACCAA }\end{array}$ & 79 & 64,3 \\
\hline Rab 7 & $\begin{array}{l}\text { Sense 5' TGAACCCATCAAACTGCACA } \\
\text { Antisense 5' CTGTGCTCTGCTCTCACTCG }\end{array}$ & 88 & 64,0 \\
\hline Rab 8A & $\begin{array}{l}\text { Sense 5' AAAAGCTGCCCTGGACTAT } \\
\text { Antisense } 5 \text { ' TGAAAAATGCGTTCTCCACA }\end{array}$ & 81 & 64,1 \\
\hline survivin & $\begin{array}{l}\text { Sense 5' CGGGGTGAGAAGGTTACAAG } \\
\text { Antisense 5' AAGCCCAGATGCTTCACTGT }\end{array}$ & 61 & 63,8 \\
\hline $\begin{array}{l}\text { Ubiquitin } \\
\text { Spesific } \\
\text { Peptidase }\end{array}$ & $\begin{array}{l}\text { Sense 5' GGATAACTCCCCTGGACCAT } \\
\text { Antisense 5' TCACTGTCTGCAGGGTGAAC }\end{array}$ & 74 & 63,8 \\
\hline
\end{tabular}

Figure 3 Changes in mRNA expression levels of selected hits, Rab5, Rab7, Rab8 and survivin as determined by real-time PCR to validate the microarray results. The RT-PCR data were normalized to a control mRNA, ubiquitin-specific peptidase and the values were converted to fold-changes using the expression level in untransformed MDCK cells at $2 \mathrm{D}$ as a reference level. The appropriate primers are shown in the lower part of the figure.

domain (rr1) of E-cadherin and with a pan-cadherin antibody (Figure 4e). A $120 \mathrm{kDa}$ band corresponding to E-cadherin was observed in all specimens and a second band with a slightly higher molecular weight was detected with E-cadherin antibody to the cytoplasmic domain and two extra bands with the pan-cadherin antibody in the blot of untransformed cells in 2D (Figure 4e). They may correspond to propeptides or in the case of pan-cadherin, also to $\mathrm{N}$-cadherin or cadherin 6, because the MDCK cells have been reported to express E-cadherin as well as cadherin-6 (K-cadherin) and in low levels also $\mathrm{N}$-cadherin. ${ }^{27,28}$ Hence, Src activation did not induce expression of new members of the cadherin family, nor altered the expression of E-cadherin.

The presence of survivin in MDCK cells with or without $\mathrm{v}$-Src was also confirmed by western blotting the cell lysates from $2 \mathrm{D}$ and $3 \mathrm{D}$ cultures (Figure $4 \mathrm{f}$ ). The results are in line with the RT-PCR results: a clearly visible band of survivin in untransformed or ts-Src MDCK cells 2D environment, nil in MDCK cells grown in 3D Matrigel environment and its reappearance in ts-Src MDCK cells in 3D environment. The results support the view that the cell behaviour in a $3 \mathrm{D}$ environment resembles that in tissues, because the expression of survivin in normal tissues is extremely low, whereas it is increased in several cancers. ${ }^{29}$

\section{Phenotype of the MDCK cells with and without v-Src Expression in 2D and 3D Environment}

The microarray results did not indicate any large changes in the gene expression levels by v-Src in cells grown on 2D dishes. However, the phenotype was completely changed, as 
shown in Figure $4 \mathrm{a}$ and $\mathrm{b}$. In ts-Src MDCK cells grown to confluency at $+40.5^{\circ} \mathrm{C}$ E-cadherin colocalized with all catenins at $\mathrm{AJs}$ (Figure 4a), whereas at $35^{\circ} \mathrm{C}$ a complete reorganization of junctional complexes had occurred and E-cadherin was seen in the cytoplasm and in the perinuclear area in vesicles with variable sizes. It co-localized in large vesicles with $\beta$-catenin and occasionally also with p120catenin (Figure 4b). Untransformed MDCK cells formed as an epithelial monolayer independently of the temperature (data not shown).

Within 3D matrix environment untransformed MDCK cells formed spherical cysts with some apoptotic cells in the lumen, cadherin and $\beta$-catenin delineating the lateral walls and actin at the apical surfaces facing the lumen. A tight junction (TJ) marker ZO-1 was very tightly delineating the apical part of the cells and an apoptotic marker, caspase-3 cleaved form antibody stained apoptotic cell fragments inside the lumen of untransformed MDCK cell cysts (Figure 4c). The results are consistent with previous observations shown by Rahikkala et al. ${ }^{17}$ and Yu et al. ${ }^{30,31}$ Ts-Src-transformed MDCK cells formed spherical clusters filled with cells and there was no cavity or lumen in the centre (Figure 4d). Instead, there were clearly two cell populations: the cells facing the extracellular matrix were cubic with cadherin molecules delineating the lateral membranes and basal surfaces, and the others remaining inside the spheres were rounded, void of apico-basal axis and showed very strong actin staining. ZO-1 was seen in short fragments throughout the cell cyst and the cell clusters were completely void of the apoptotic marker caspase-3 (Figure $4 \mathrm{c}$ and $\mathrm{d}$ ). a

Confocal microscopy images of Src-MDCK cells grown on dishes at $40.5 \mathrm{oC}$
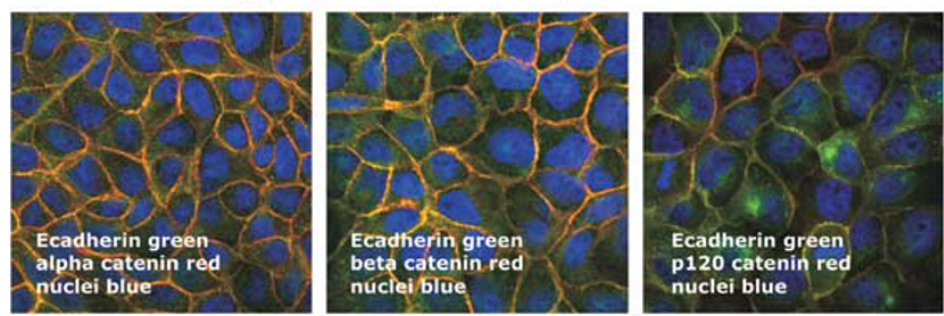

b Confocal microscopy images of Src-MDCK cells grown on dishes at $35 \mathrm{oC}$
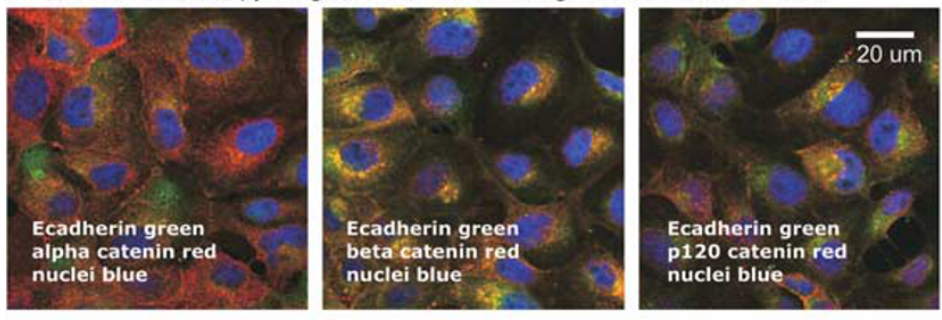

C Confocal microscopy images of untransformed MDCK cells grown at 37 oC in $3 D$ gel
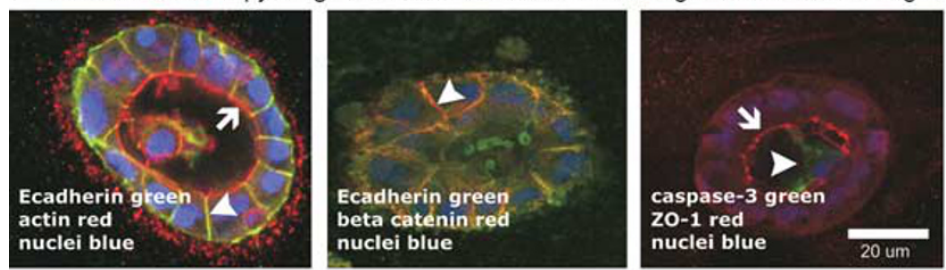

d Confocal microscopy images of Src-MDCK cells grown at $35 \mathrm{oC}$ in $3 \mathrm{D}$ gel
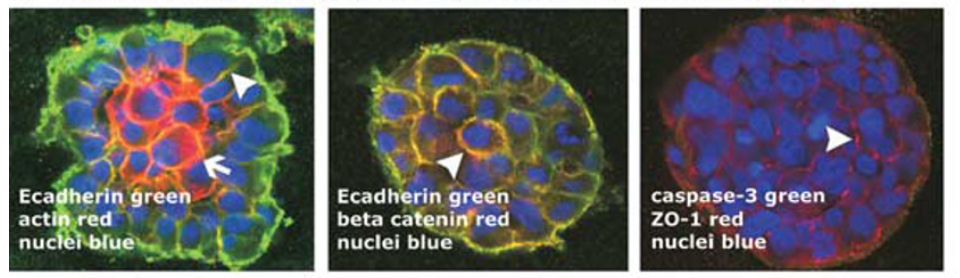

e Western blotting of cadherin

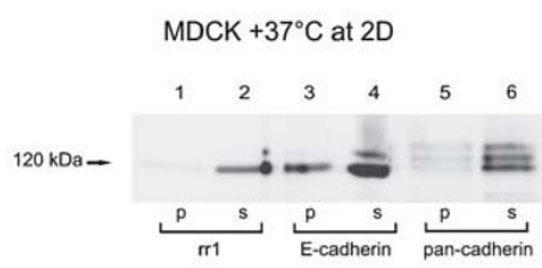

Src-MDCK $+35^{\circ} \mathrm{C}$ at $2 \mathrm{D}$

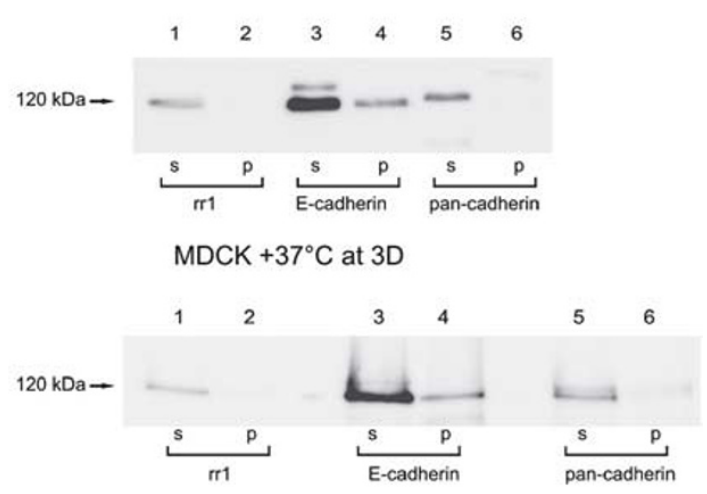

Src-MDCK $+35^{\circ} \mathrm{C}$ at $3 \mathrm{D}$

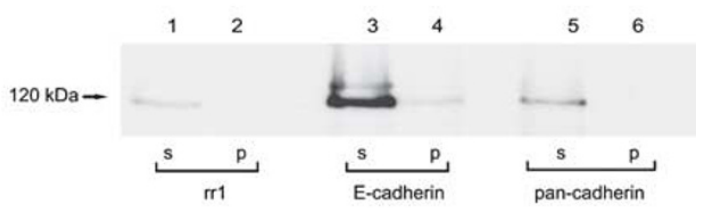

f

Western blotting of survivin

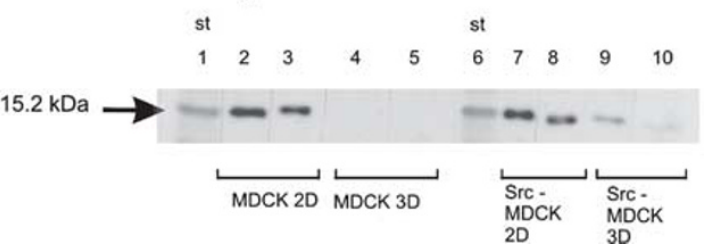




\section{Functional Assays: Mitochondrial Activity in Untransformed and v-Src-Transformed MDCK Cells in 3D Environment; Cadherin Recycling \\ Mitochondrial activity}

The essential hallmarks of cancer include altered metabolism, that is, increase in glycolysis and the resistance of cancer cells' mitochondria against apoptosis-induced permeabilization. ${ }^{32}$ To analyze the mitochondrial activity of the cells we took advantage of two fluorescent markers which, when incorporated into cells, emit fluorescence light, Mitotracker Green representing mitochondrial mass and Mitotracker Orange mitochondrial oxidative capacity, respectively. ${ }^{33}$ We have taken the ratio of Mitotracker Orange to Mitotracker Green signal as a mitochondrial metabolic index representing the proportion of the actively respirating mitochondria from the total mitochondrial mass. The results are shown in Figure 5. In untransformed cells the ratio was high for one or two days and then rapidly declined indicating loss of mitochondrial membrane potential and increase in mitochondrial membrane permeability. It was in line with the visual inspection of the cell cyst life span: the cells started dividing after plating and the lumen formation began in 2 to 3 days after which the cell proliferation rate decreased and apoptosis was induced. In ts-Src-transformed MDCK cells the proportion of active mitochondria was higher than in untransformed MDCK cells from the first day and remained so up to 7 days (Figure 5). Hence, in ts-Srctransformed cells mitochondrial membrane permeability necessary for apoptosis seemed to be inhibited by v-Src.

\section{Cadherin recycling}

Constitutive endocytosis of cadherins has been observed in cells that display apparently stable cell-cell contacts. ${ }^{34,35} \mathrm{We}$ wished to compare the efficiency of cadherin internalization and recycling in ts-Src MDCK cells at 2D with and without Src activation. For that purpose, we monitored the fate of surface cadherin labeled on ice with cadherin antibody (rr1) after warming the cells to $+40.5^{\circ} \mathrm{C}$ or $35^{\circ} \mathrm{C}$ (Figure 6). In addition, we stained $\beta$-catenin to see when E-cadherin- $\beta$ catenin complex was disintegrated. When the cells were fixed on ice, rrl staining was seen on the cell surface, mostly at the edges of cell islets. In $30 \mathrm{~min}$ after warming the cells either to $+40.5^{\circ} \mathrm{C}$ or $+35^{\circ} \mathrm{C}$, rr1-labelled E-cadherin was seen in the cell interior in apical vesicles occasionally void of $\beta$-catenin, but it co-localized with $\beta$-catenin at basal surfaces. The quantitative co-localization analysis of E-cadherin and $\beta$-catenin in the cell interior is shown in Table 1. In $30 \mathrm{~min}$ after internalization co-localization coefficients were higher at $+35^{\circ} \mathrm{C}$ suggesting that at permissive temperature $\mathrm{AJs}$ are disintegrating and both proteins are internalized together. Within $60 \mathrm{~min}$ incubation at $+40.5^{\circ} \mathrm{C}$, rr1-labelled E-cadherin was seen partially in apical vesicles and partially accumulated back to lateral membranes. Co-localization coefficient for E-cadherin in apical vesicles was very low at $+40.5^{\circ} \mathrm{C}$ suggesting that they belong to the clathrin-mediated recycling route where catenins are released from E-cadherin upon internalization. ${ }^{36}$ In the cells incubated $60 \mathrm{~min}$ at $+35^{\circ} \mathrm{C}$ only a thin cadherin layer was found at lateral membranes and the majority remained in cytoplasm and in apical vesicles void of $\beta$-catenin. Hence, cadherin internalization took place at both nonpermissive and permissive temperature, but recycling was more efficient at $+40.5^{\circ} \mathrm{C}$. This phenomenon may be related to decreased expression of rab proteins, but also to the disintegration of cytoskeletal structures and, thus, impaired

Figure 4 (a) Confocal microscopy images of E-cadherin double stained with $\alpha$-catenin, $\beta$-catenin and p120catenin through a central part of the monolayer of v-Src-transformed MDCK cells grown at $+40.5^{\circ} \mathrm{C}$ in cell culture dishes to confluency. E-cadherin is shown in green, catenins in red and nuclei blue. The cells have an epithelial morphology, cadherin is at lateral membranes co-localizing with all catenins and occasionally it is seen at Golgi area. (b) Confocal microscopy images of E-cadherin double stained with $\alpha$-catenin, $\beta$-catenin and p120catenin through a central part of the monolayer of $v$-Src-transformed MDCK cells grown at $+35.0^{\circ} \mathrm{C}$ in cell culture dishes to confluency. E-cadherin is shown in green, catenins in red and nuclei blue. The cells have a fibroblastic morphology, cadherin is at Golgi area colocalizing with $\beta$-catenin and p120catenin, but not with $\alpha$-catenin. Bar: $20 \mu$ m. (c) Confocal microscopy images of E-cadherin double stained with actin and $\beta$-catenin and caspase-3 double stained with ZO- 1 through a central part of the cell cyst of untransformed MDCK cells grown at $+37^{\circ} \mathrm{C}$ in a mixture of collagen I and Matrigel. E-cadherin and caspase-3 are shown in green, actin, $\beta$-catenin and ZO- 1 in red and nuclei blue. The cells have formed a spherical cyst with a lumen inside. Cadherin is at lateral membranes (arrow head) co-localizing with $\beta$-catenin, actin is delineating the apical surfaces (arrow), caspase- 3 is showing the remnants of apoptotic cells captured within the lumen (arrow head) and ZO- 1 is at tight junctions close to the apical surface (arrow). Bar: $20 \mu \mathrm{m}$. (d) Confocal microscopy images of E-cadherin double stained with actin and $\beta$-catenin and caspase-3 double stained with ZO-1 through a central part of the cell cluster of v-Src-transformed MDCK cells grown at $+35^{\circ} \mathrm{C}$ in a mixture of collagen I and Matrigel. E-cadherin and caspase-3 are shown in green, actin, $\beta$-catenin and ZO-1 in red and nuclei blue. The cells have formed a spherical cluster filled with cells. Cadherin is at lateral and basal membranes (arrow head) co-localizing with $\beta$-catenin, actin is delineating the cell membranes of cells captured inside the cluster (arrow), caspase-3-staining is not visible and ZO-1 is in short pieces at cell membranes through the cell cluster (arrow head). (e) Immunoblot analysis showing expression of cadherin in Triton soluble (s) and cytoskeletal ( $p$ ) fractions of untransformed and v-Src transformed MDCK cells grown to confluency at 2D cell culture dishes or in 3D Matrigel visualized with E-cadherin antibody to extracellular domain ( $r$ 1, lanes 1 and 2), E-cadherin antibody to the cytoplasmic domain (E-cadherin, lanes 3 and 4) and pan-cadherin antibody to the cytoplasmic domain (lanes 5 and 6 ). A 120 kDa band corresponding to E-cadherin was observed in all specimens with all three cadherin antibodies, the majority of cadherin being in the Triton-soluble fraction. A second band with a slightly higher molecular weight was detected with E-cadherin antibody and two extra bands with pan-cadherin antibody. (f) Immunoblot analysis showing expression of survivin in cell lysates from untransformed and v-Src transformed MDCK cells grown to confluency at 2D cell culture dishes or in 3D Matrigel visualized with survivin antibody diluted to 1:500 (lanes 2, 4, 7 and 9) or 1:1000 (lanes 3, 5, 8 and 10). A 16 kDa band corresponding to survivin was observed in both untransformed and v-Src-transformed cells grown at 2D (lanes 2, 3, 7 and 8). There was hardly anything visible in the lanes from untransformed cells grown in 3D Matrigel (lanes 4 and 5) and a slight band in v-Src-transformed cells grown in 3D Matrigel at $+35^{\circ} \mathrm{C}$ (lanes 9 and 10 ). Lanes 1 and 6 show the $15.2 \mathrm{kDa}$ standard. 
a
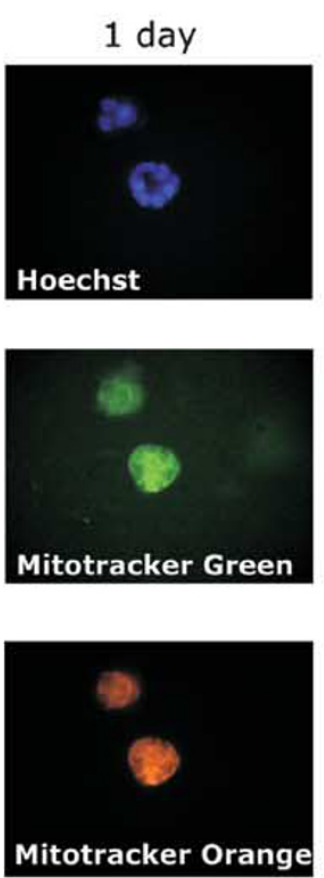

$O / G=6.82$
$(n=59)$

b

1 day
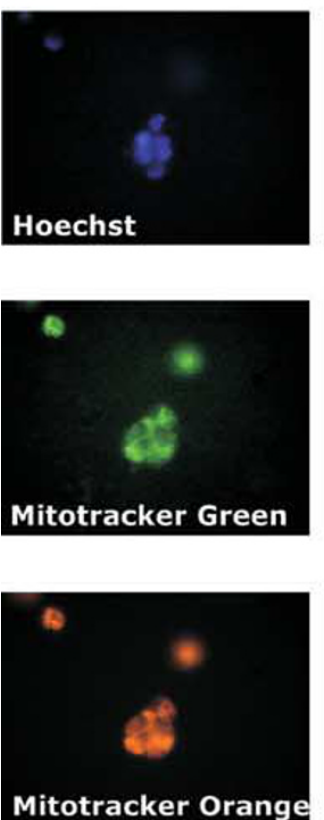

$\mathrm{O} / \mathrm{G}=7.79$

$(n=49)$
2 days
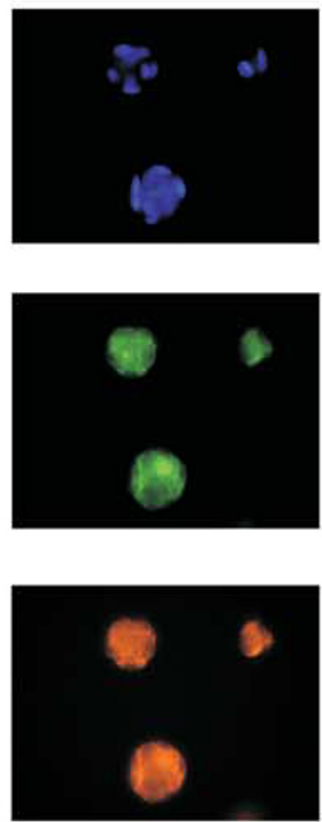

4.27

$(n=54)$

2.29

$(n=55)$

Src-MDCK cells

3 days
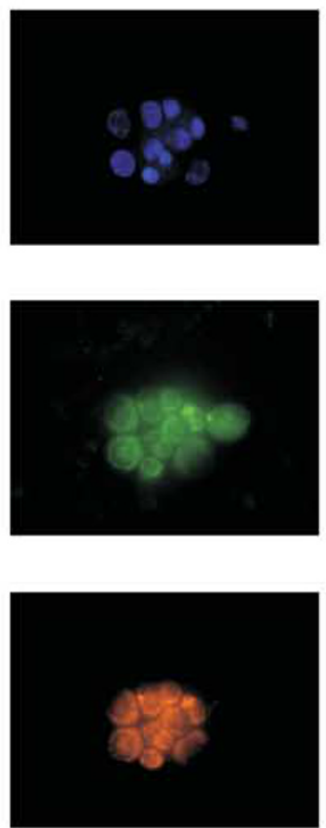

5.33

$(n=31)$

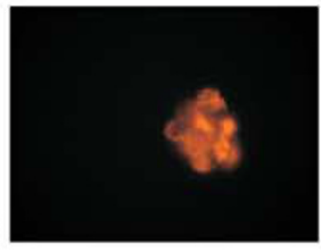

4.48

$(n=46)$
7 days
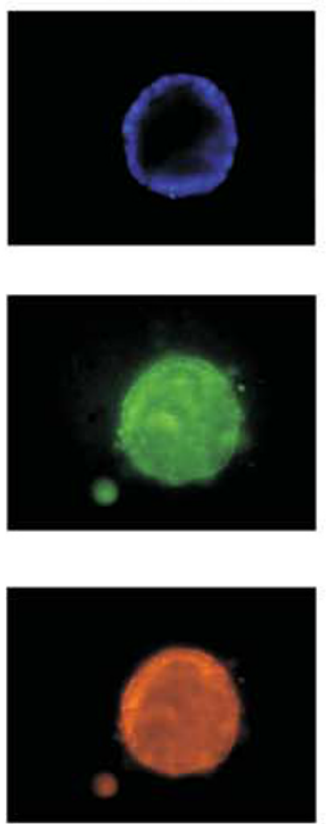

\subsection{2}

$(n=60)$

7 days
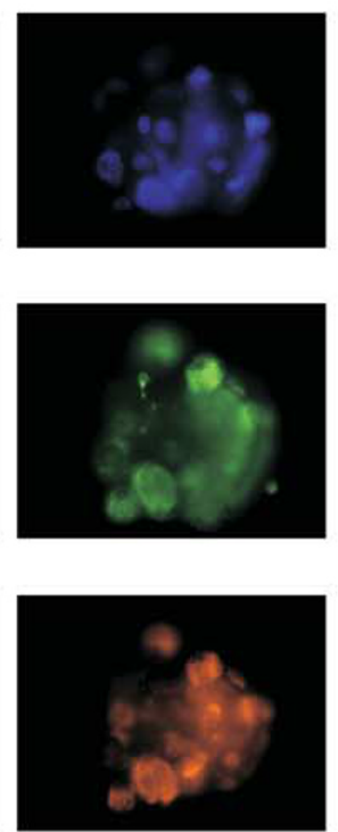

3.00

$(n=54)$
8 days
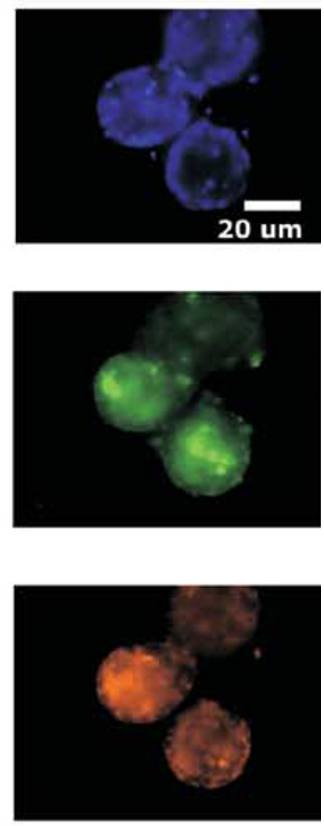

1.57

$(n=63)$

8 days
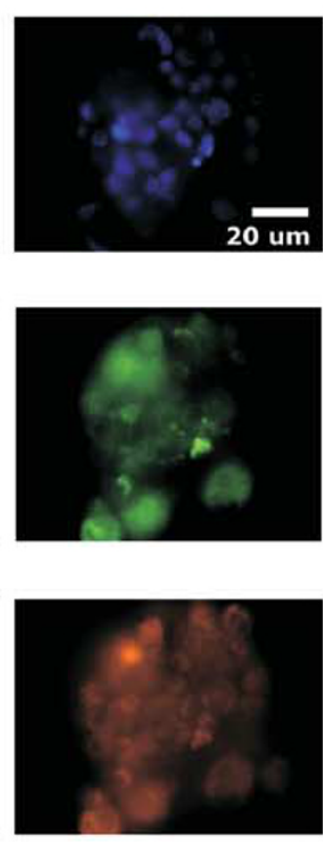

1.28

$(n=48)$ 
transportation machinery caused by $\mathrm{v}$-Src at permissive temperature.

\section{DISCUSSION}

Extensive remodeling of tissues occurs during embryogenesis and carcinogenesis and in some diseases like fibrosis or in the process of wound healing. Central assets in these processes are cell proliferation, apoptosis and migration. The majority of the information on the regulation of these events has been gathered with cultured cells. A classical model is MDCK cells, which grown on plastic or even permeable filters form a monolayer, but when cultured in collagen I or Matrigel start an intrinsic differentiation program and form spherical luminal monolayers. ${ }^{2}$ The basic difference between the two culture systems is that in $2 \mathrm{D}$ cultures the underlying substrate provides a cue for the establishment of the polarization axis, whereas MDCK cells within the gel create their polarization cue autonomously, starting from a nearly isotropic situation. ${ }^{37}$ The MDCK cells grown in 3D environment differ from a $2 \mathrm{D}$ culture in their ability to induce apoptosis and start lumen formation. Martin-Belmonte et al., ${ }^{2}$ showed that mechanism of lumen formation can be either hollowing or cavitation, the preferred mode being dependent on the cell density. The loss of ECM contact favors apoptosis, because a pro-apoptotic protein BAD transfected to MDCK cells grown on 2D substrate was not sufficient to induce apoptosis, but strongly augmented apoptosis in suspension culture. ${ }^{38}$ Another widely used model for lumen formation is human mammary MCF-10A cell line. The molecular mechanism underlying lumen formation in MCF-10A 3D acini or in suspension seemed to require the pro-apoptotic factor BIM. Downregulation of BIM or overexpressing the anti-apoptotic factor BCL-2 prevented efficient luminal clearing, but only delayed lumen formation which might also involve autophagy of central cells. ${ }^{11}$

There is surprisingly little information on the alterations in the gene expression levels in the cells cultured in 3D in comparison with those grown in monolayers. In our hands, over 6000 genes changed their expression when the MDCK cells were cultivated in 3D Matrigel instead of cell culture dishes. The most striking feature was the complete lack of cytoskeletal or junctional proteins in the list of altered genes. There were no changes in the gene expression of components in the apoptosis machinery, such as BIM or BAD. Hence, the build-up of the cyst with an apico-basal axis, lumen inside and the basal surface facing ECM in 3D gel can be considered as a default program of MDCK cells and there is no need to alter the expression profile of the building components. The most interesting observation was the expression of an apoptosis inhibitor, survivin in both untransformed and ts-Src-transformed MDCK cells in 2D environment, completely lack of expression in 3D environment of untransformed cells and reappearance in ts-Src-transformed cells in 3D environment. This coincided with the reduced mitochondrial membrane permeability, formation of lumen and appearance of caspase-3 in the untransformed cells and continued proliferation in $\mathrm{v}$-Src-transformed cells. We are not aware of any previous data on the role of downregulation of an apoptosis inhibitor, survivin in the lumen formation in either MDCK or MCF-10A cells, although its expression level is normally very low in adult tissues and elevated in several cancers. ${ }^{29}$ Survivin is also highly expressed in keratinocyte stem cells and was downregulated in $6 \mathrm{~h}$ in a suspension culture in the presence of anti- $\beta 1$ integrin-neutralizing antibody, which induced anoikis of stem cells. ${ }^{39}$ The expression of survivin in non-transformed MDCK cells grown on 2D cell culture dishes might explain why the cells did not undergo apoptosis. There are many examples on the effect of the substrate rigidity on the cell behaviour and a common conclusion is that the matrix stiffness could affect integrin signaling and promote malignant transformation of the tissue. ${ }^{40}$ Survivin expression is one example on the malignant behaviour of non-transformed MDCK cells grown on 2D plastic surface.

There are only a few reports on the gene expression profiles under the influence of Src oncogene: Sung et al. ${ }^{41}$ have carried out a high throughput analysis of gene expression profiles between mock-transfected and $\mathrm{v}$-Src transfected rat fibroblasts. They identified significant overexpression of DNA methyltransferase 1 in v-Src-transfected fibroblasts, whereas several tumor suppressor genes were downregulated by $\mathrm{v}-\mathrm{Src}$, but could be reexpressed after treatment with a demethylating agent. A similar analysis was carried out by Masker et al. ${ }^{42}$ using chicken embryo fibroblasts transfected with Rous Sarcoma virus. They observed 811 genes modulated by $\mathrm{v}$-Src. The set of strongly induced genes in their analysis contained vasoactive intestinal polypeptide, MAP kinase phosphatase 2 and follistatin, whereas the set of

Figure 5 Video microscopy images of untransformed (a) and v-Src-transformed MDCK cells (b) cultivated at $+35^{\circ} \mathrm{C}$ in Matrigel for $1,2,3,7$ and 8 days, labelled every day with a mixture of a DNA-marker Hoechst (blue), Mitotracker Green (green) and Mitotracker Orange $\mathrm{CM}-\mathrm{H}_{2} \mathrm{TM}$ Ros (orange) for 15 min in the cell culture stove and illuminated under an Olympus Cell M video microscope using a $\times 40$ water immersion objective and appropriate filters for blue, green and red channel. In untransformed MDCK cells lumen formation is visible already on the third day of culture, whereas in v-Src-transformed cells there is no organized structure in the cell cluster, which only increases in size. Apoptotic bodies are visible in Hoechst-stained untransformed MDCK cells in images taken on the seventh and eighth culture days. The average value for the ratio of the intensity of selected regions of interest (ROI) in red and green channel $(\mathrm{O} / \mathrm{G})$ is shown below the images and the number of measured ROls is shown in parenthesis. The ROls were chosen both from the surface and the interior of the cell cluster and included several cells, but always so that one could distinguish the mitochondria. The statistical $t$-test showed that in each day the average ratio values in MDCK cells differed statistically significantly from the ones in v-Src-transformed MDCK cells with the confidential limit $P<0.05$. Bar: $20 \mu \mathrm{m}$. 

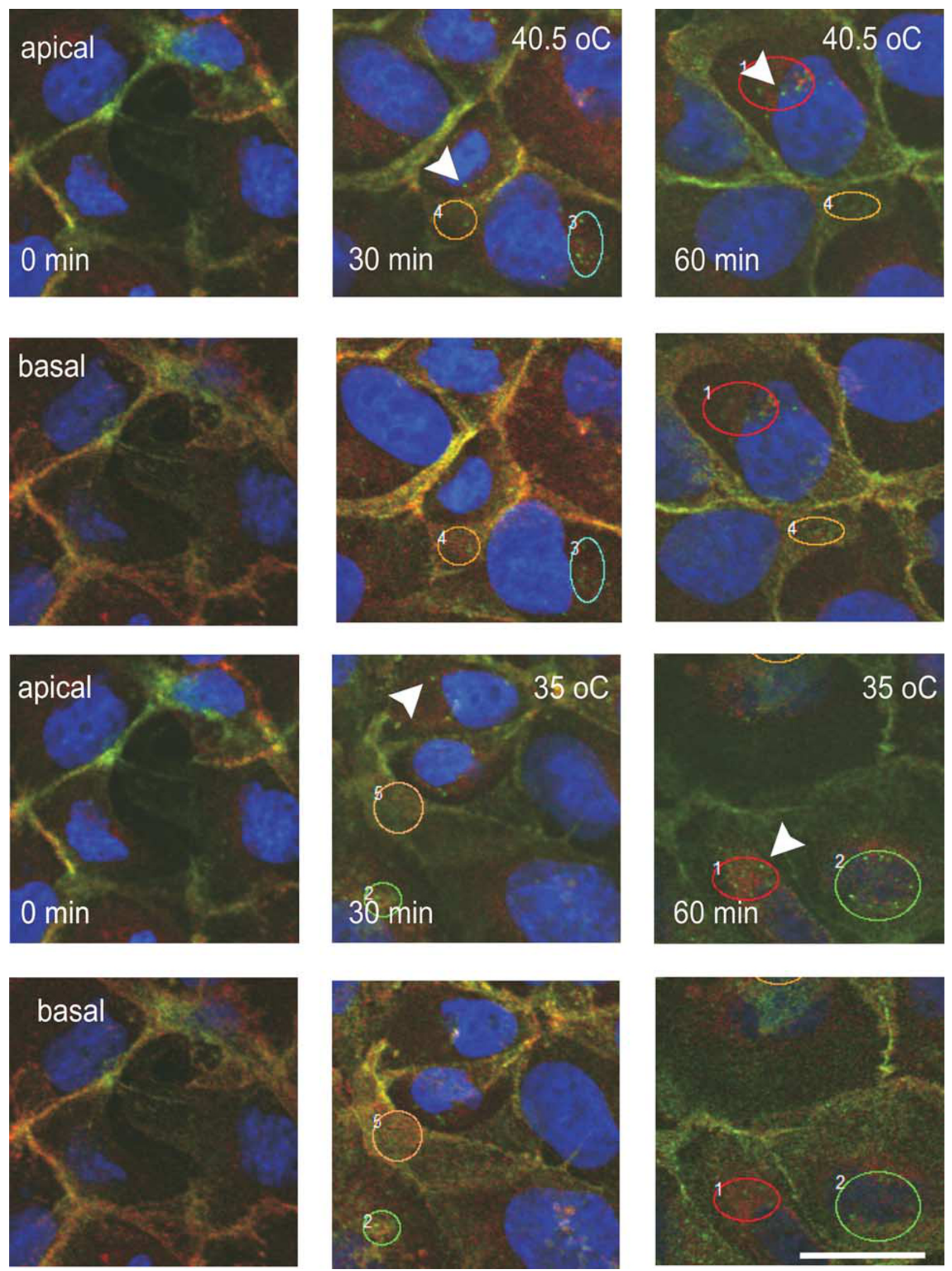
strongly repressed genes contained TGF $\beta 3$, TGF $\beta$-induced gene and deionidase. None of these can be directly linked to distintegration of AJs and EMT. In our hands very few genes changed their expression upon activation of $\mathrm{v}-\mathrm{Src}$ in MDCK cells grown on dishes with our strict criteria that the genes must be altered in all three comparisons to the same direction: (1) untransformed MDCK cells, (2) v-Src-transformed MDCK cells grown at non-permissive temperature and (3) v-Src-transformed MDCK cells with Src activity inhibited by $\mathrm{pp} 2$ were separately compared with $\mathrm{v}$-Src-transformed MDCK cells grown at permissive temperature. This might result in the loss of some Src targets, but the message was still clear that the expression of junctional proteins, cadherin or catenins was not affected by v-Src activity. We have shown earlier that p120catenin is rapidly phosphorylated in v-Srctransformed MDCK cells shifted to permissive temperature, whereas $\beta$-catenin and E-cadherin are phosporylated already at non-permissive temperature. ${ }^{13}$ Most likely, the rapid responses in MDCK cells by $\mathrm{v}$-Src leading to EMT on 2D conditions are due to altered protein-protein interactions caused phosphorylations of cadherin and catenins by v-Src.

The alterations in gene expression between untransformed and $\mathrm{v}$-Src-transformed MDCK cells grown in 3D environment were more evident and many genes linked to cell signaling, proliferation, energy metabolism and transport were changed upon $\mathrm{v}$-Src activation. Two interesting proteins, Nanos and Kaiso increased their expression by v-Src activation. They as well as survivin are functionally linked to localization and expression E-cadherin and p120catenin and participate or are targets of the $\beta$-catenin/TCF4/LEF pathway. Kaiso acts as its repressor and inhibits transcription of the target genes and the repression is relieved by entrance of p 120 catenin molecules to nucleus. ${ }^{26}$ Nong et al. ${ }^{43}$ have observed that p120catenin overexpression enhanced $\beta$-catenin-E-cadherin binding and downregulated expression of survivin in a hepatoma cell line resulting in decreased cell proliferation. Caveolin-1 inhibits expression of survivin, associates with $\beta$-catenin and regulates clathrin-independent endocytosis of cadherin. ${ }^{44}$ Nanos, a p120catenin-binding protein, disturbs E-cadherin-dependent cell-cell adhesion by inducing relocalization of junctional proteins to the cytoplasm. ${ }^{25}$ Hence, there is a close link between the existence of tight cellcell adhesion, proliferation and apoptosis in the processes of epithelial differentiation or transformation and p120catenin together with $\beta$-catenin has a central role in the regulatory pathways as components of the cell-cell junctions and as regulators of gene expression.

Growth factors and prostaglandins among other factors also affect altered gene expression during malignant transformation. For instance, insulin-like growth factor IGF1 has been shown to mediate resistance to anoikis-induced apoptosis by inhibiting mitochondrial damage and increasing expression of survivin and antiapoptotic members of the BCL 2 family. ${ }^{45}$ Prostaglandin E2 has been shown to block the ability of caveolin- 1 to sequester $\beta$-catenin to the plasma membrane and enhance its stability in the cytosol resulting in increased expression of survivin. ${ }^{46}$

In this study we have shown that $\mathrm{v}$-Src activation has completely different consequences in $2 \mathrm{D}$ and $3 \mathrm{D}$ environment: In 2D it induced EMT and in 3D it increased cell proliferation and inhibited apoptosis. Hence, conclusions made on experiments carried out in 2D should be transferred to cancer tissues with great care. A good example of these differences is the observation on human epidermal growth factor receptors HER2 and HER3, which in 2D culture of cancer cells form heterodimers, whereas in multicellular spheroids HER2 homodimers are formed, resulting in a complete different downstream signaling cascades. ${ }^{47}$ Seeberger et al. ${ }^{48}$ goes even further and claims that EMT is an artifact of cell culture. The lack of survivin expression in untransformed MDCK cells and its re-expression due to $\mathrm{v}-\mathrm{Src}$ in 3D environment gives, however, a strong clue that $\mathrm{v}$-Src and survivin are important partners in the transformation process when apoptosis is inhibited and cell proliferation increased.

Supplementary Information accompanies the paper on the Laboratory Investigation website (http://www.laboratoryinvestigation.org)

\section{ACKNOWLEDGEMENTS}

This work was supported by The Cancer Society of Northern Finland, Finnish Medical Foundation and Oskar Öflund Foundation pre-doctoral fellowships to Mira Töyli. Keith Johnson and Margaret Wheelock (Nebraska Medical Center, Omaha, NE, USA) are kindly acknowledged for providing the $\alpha$-catenin antibody (clone Ig5), Kai Simons, EMBL, Heidelberg, FRG for providing Madin-Darby canine kidney cells (MDCK, strain II), Walter Birchmeier and Jürgen Behrens (Max Delbrück Center for Molecular Medicine, Berlin, Germany) for providing the ts-src-transformed MDCK cells. We want to thank Marja-Liisa Martti, Marja Tolppanen and Antti Viklund for their skilful technical assistance and Christin Nenner for help in graphical presentations.

Figure 6 Confocal microscopy images of internalization of rr1-cadherin antibody-labeled cell surface cadherin in v-Src transformed MDCK cells grown at $+40.5^{\circ} \mathrm{C}$ in cell culture dishes to confluency, surface-labeled on ice with $\mathrm{rr} 1$ antibody and warmed for $30 \mathrm{~min}$ or $60 \mathrm{~min}$ to $+40.5^{\circ} \mathrm{C}$ or $+35^{\circ} \mathrm{C}$ before fixation. Cadherin is shown in green, $\beta$-catenin in red and nuclei blue. In cells fixed on ice, rr1 staining was seen at lateral membranes near apical surface. In 30 min after warming to $+40.5^{\circ} \mathrm{C}$ or $+35^{\circ} \mathrm{C}$, rr1-labelled E-cadherin was seen in the cell interior in apical vesicles void of $\beta$-catenin (arrow head), but co-localizing with $\beta$-catenin at basal surfaces. Within $60 \mathrm{~min}$ after warming to $+40.5^{\circ} \mathrm{C}$, rr1-labelled E-cadherin partially accumulated back to lateral membranes, partially remained in apical vesicles (arrow head), whereas in cells incubated at $35^{\circ} \mathrm{C}$, much less $\mathrm{rr} 1$-conjugated cadherin was found at lateral membranes and the majority remained in cytoplasm and in apical vesicles void of $\beta$-catenin (arrow head). ROls occasionally seen in images were used for the quantitative co-localization analysis presented in Table 1. Bar: $20 \mu \mathrm{m}$. 


\section{DISCLOSURE/CONFLICT OF INTEREST}

The authors declare no conflict of interest.

1. Chung S, Andrew DJ. The formation of epithelial tubes. J Cell Sci 2008;121:3501-3504.

2. Martin-Belmonte $F, Y u$ W, Rodriguez-Fraticelli $A E$, et al. Cell-polarity dynamics controls the mechanism of lumen formation in epithelial morphogenesis. Curr Biol 2008;18:507-513.

3. Debnath J, Mills KR, Collins NL, et al. The role of apoptosis in creating and maintaining luminal space within normal and oncogeneexpressing mammary acini. Cell 2002;111:29-40.

4. Perez-Moreno M, Fuchs E. Catenins: keeping cells from getting their signals crossed. Dev Cell 2006;11:601-612.

5. Fox DT, Peifer M. Cell adhesion: separation of p120's powers? Curr Biol 2007; 17:R24-R27.

6. Jin T, Fantus Gl, Sun J. Wnt and beyond Wnt: multiple mechanisms control the transcriptional property of beta-catenin. Cell Signal 2008;20:1697-1704.

7. Drees F, Pokutta S, Yamada S, et al. Alpha-catenin is a molecular switch that binds E-cadherin-beta-catenin and regulates actin-filament assembly. Cell 2005;123:903-915.

8. Yamada S, Pokutta S, Drees $F$, et al. Deconstructing the cadherincatenin-actin complex. Cell 2005;123:889-901.

9. Capaldo CT, Macara IG. Depletion of E-cadherin disrupts establishment but not maintenance of cell junctions in Madin-Darby canine kidney epithelial cells. Mol Biol Cell 2007;18:189-200.

10. Thiery JP, Sleeman JP. Complex networks orchestrate epithelialmesenchymal transitions. Nat Rev Mol Cell Biol 2006;7:131-142.

11. Mailleux AA, Overholzer M, Brugge JS. Lumen formation during mammary epithelial morphogenesis. Cell Cycle 2008;7:57-62.

12. Behrens J, Vakaet L, Friis R, et al. Loss of epithelial differentiation and gain of invasiveness correlates with tyrosine phosphorylation of the E-cadherin/beta-catenin complex in cells transformed with a temperature-sensitive v-SRC gene. J Cell Biol 1993;120:757-766.

13. Palovuori R, Sormunen R, Eskelinen S. SRC-induced disintegration of adherens junctions of madin-darby canine kidney cells is dependent on endocytosis of cadherin and antagonized by Tiam-1. Lab Invest 2003;83:1901-1915.

14. Alema S, Salvatore AM. p120 catenin and phosphorylation: Mechanisms and traits of an unresolved issue. Biochim Biophys Acta 2007;1773:47-58.

15. Miyashita Y, Ozawa M. A dileucine motif in its cytoplasmic domain directs beta-catenin-uncoupled E-cadherin to the lysosome. J Cell Sci 2007;120:4395-4406.

16. Fujita $Y$, Krause $G$, Scheffner $M$, et al. Hakai, a c-Cbl-like protein, ubiquitinates and induces endocytosis of the E-cadherin complex. Nat Cell Biol 2002;4:222-231.

17. Rahikkala M, Sormunen R, Eskelinen S. Effects of src kinase and TGFbeta1 on the differentiation and morphogenesis of MDCK cells grown in three-dimensional collagen and Matrigel environments. J Pathol 2001;195:391-400.

18. Debnath J, Muthuswamy SK, Brugge JS. Morphogenesis and oncogenesis of MCF-10A mammary epithelial acini grown in threedimensional basement membrane cultures. Methods 2003;30:256-268

19. Torkko JM, Manninen A, Schuck S, et al. Depletion of apical transport proteins perturbs epithelial cyst formation and ciliogenesis. J Cell Sci 2008;121:1193-1203.

20. Gumbiner B, Simons K. A functional assay for proteins involved in establishing an epithelial occluding barrier: identification of a uvomorulin-like polypeptide. J Cell Biol 1986;102:457-468.

21. Li C, Wong WH. Model-based analysis of oligonucleotide arrays: expression index computation and outlier detection. Proc Natl Acad Sci USA 2001;98:31-36.

22. Ling K, Bairstow SF, Carbonara C, et al. Type Igamma phosphatidylinositol phosphate kinase modulates adherens junction and E-cadherin trafficking via a direct interaction with u1B adaptin. J Cell Biol 2007;176:343-353.

23. de Diesbach P, Medts T, Carpentier S, et al. Differential subcellular membrane recruitment of Src may specify its downstream signalling. Exp Cell Res 2008;314:1465-1479.

24. Bain J, McLauchlan $H$, Elliott $M$, et al. The specificities of protein kinase inhibitors: an update. Biochem J 2003;371:199-204.
25. Strumane $\mathrm{K}$, Bonnomet $\mathrm{A}$, Stove $\mathrm{C}$, et al. E-cadherin regulates human Nanos1, which interacts with p120ctn and induces tumor cell migration and invasion. Cancer Res 2006;66:10007-10015.

26. van Roy FM, McCrea PD. A role for Kaiso - p120ctn complexes in cancer? Nature Rev Cancer 2005;5:956-964.

27. Stewart DB, Barth Al, Nelson WJ. Differential regulation of endogenous cadherin expression in Madin-Darby canine kidney cells by cell-cell adhesion and activation of beta -catenin signaling. J Biol Chem 2000;275:20707-20716.

28. Youn $\mathrm{YH}$, Hong J, Burke JM. Endogenous N-cadherin in a subpopulation of MDCK cells: distribution and catenin complex composition. Exp Cell Res 2005;303:275-286.

29. Altieri DC. Survivin, cancer networks and pathway-directed drug discovery. Nat Rev Cancer 2008;8:61-70.

30. Yu W, Datta A, Leroy $P$, et al. Beta1-integrin orients epithelial polarity via Rac1 and laminin. Mol Biol Cell 2005;16:433-445.

31. Yu W, Shewan AM, Brakeman P, et al. Involvement of RhoA, ROCK I and myosin II in inverted orientation of epithelial polarity. EMBO Rep 2008;9:923-929.

32. Kroemer G, Pouyssegur J. Tumor cell metabolism: cancer's Achilles' heel. Cancer Cell 2008;13:472-482.

33. Buckman JF, Hernandez H, Kress GJ, et al. Mitotracker labeling in primary neuronal and astrocytic cultures: influence of mitochondrial membrane potential and oxidants. J Neurosci Meth 2001;104: 165-176.

34. Le TL, Yap AS, Stow JL. Recycling of E-cadherin: a potential mechanism for regulating cadherin dynamics. J Cell Biol 1999;146:219-232.

35. Yap AS, Crampton MS, Hardin J. Making and breaking contacts: the cellular biology of cadherin regulation. Curr Opin Cell Biol 2007; 19:508-514.

36. Delva E, Kovalczyk AP. Regulation of cadherin trafficking. Traffic 2009;10:259-267.

37. Pampaloni F, Reynaud EG, Stelzer EH. The third dimension bridges the gap between cell culture and live tissue. Nat Rev Mol Cell Biol 2007;8:839-845.

38. Idogawa M, Adachi M, Minami $T$, et al. Overexpression of BAD preferentially augments anoikis. Int J Cancer 2003;107:215-223.

39. Marconi A, Dallaglio K, Lotti $R$, et al. Survivin identifies keratinocyte stem cells and is downregulated by anti-beta1 integrin during anoikis. Stem Cells 2007;25:149-155.

40. Paszek MJ, Zahir N, Johnson KR, et al. Tensional homeostasis and the malignant phenotype. Cancer Cell 2005;8:241-254.

41. Sung J, Turner J, McCarthy S, et al. Oncogene regulation of tumor suppressor genes in tumorigenesis. Carcinogenesis 2005;26: 487-494.

42. Masker K, Golden A, Gaffney CJ, et al. Transcriptional profile of Rous sarcoma virus transformed chicken embryo fibroblasts reveals new signaling targets of viral-src. Virology 2007;364:10-20.

43. Nong CZ, Pan LL, He WS, et al. p120ctn overexpression enhances betacatenin-E-cadherin binding and down regulates expression of survivin and cyclin D1 in BEL-7404 hepatoma cells. World J Gastroenterol 2006;12:1187-1191.

44. Torres VA, Tapia JC, Rodriguez DA, et al. E-cadherin is required for caveolin-1-mediated down-regulation of the inhibitor of apoptosis protein survivin via reduced beta-catenin-Tcf/Lef-dependent transcription. Mol Cell Biol 2007;27:7703-7717.

45. Hilmi C, Larribere L, Giuliano S, et al. IGF1 promotes resistance to apoptosis in melanoma cells through an increased expression of BCL2, BCL-X(L), and survivin. J Invest Dermatol 2008;128:1499-1505.

46. Rodriguez DA, Tapia JC, Fernandez JG, et al. Caveolin-1-mediated suppression of cyclooxygenase- 2 via a beta-catenin-Tcf/Lef-dependent transcriptional mechanism reduced prostaglandin E2 production and survivin expression. Mol Biol Cell 2009;20:2297-2310.

47. Pickl M, Ries $\mathrm{CH}$. Comparison of $3 \mathrm{D}$ and $2 \mathrm{D}$ tumor models reveals enhanced HER2 activation in 3D associated with an increased response to trastuzumab. Oncogene 2009;28:461-468.

48. Seeberger KL, Eshpeter A, Rajotte RV, et al. Epithelial cells within the human pancreas do not coexpress mesenchymal antigens: epithelialmesenchymal transition is an artifact of cell culture. Lab Invest 2009;89:110-121.

49. Pawley JB. Handbook of Biological Confocal Microscopy. Springer Sicence+Business Media, LLC: New-York, 2006. 